\title{
O pretuguês como comunidade de prática: concordância nominal e identidade racial
}

\author{
The "pretuguês" as a community of practice: nominal agreement and racial \\ identity
}

\author{
Fernanda de Oliveira Cerqueira ${ }^{1}$ \\ Universidade Federal da Bahia
}

- RESUMO: O presente trabalho visa demonstrar que a ausência de concordância de número em sintagmas nominais, reflete aspectos estilísticos da língua provenientes de identidade racial, como movimento emancipatório (HOOKS, 2008), quando produzidos no dialeto hip hop (SOUZA, 2009). Para tanto, é feita adoção da terceira onda da sociolinguística (ECKERT, 2005, 2012), a fim de identificar, em dados extraídos de músicas do gênero musical rap, que esse uso está diretamente atrelado a aspectos estilísticos decorrentes de consciência e identidade racial. Nesse sentido, assume-se que marcas linguísticas do pretuguês (GONZALEZ, 1983), no hip hop, implicam na existência de comunidades dessa prática.

- PAlaVRAS-CHAVE: Pretuguês; Concordância nominal; Comunidade de prática; Identidade racial.

- ABSTRACT: The present work aims to that the absence of the number agreement in noun phrases, reflects stylistic aspects of the language arising from racial identity, such as the emancipatory movement (HOOKS, 2008), when it is produced in the hip hop dialect (SOUZA, 2009). Therefore, the third wave of sociolinguistics is adopted (ECKERT, 2005, 2012), in order to identify, in data extracted from songs of the rap musical genre, that the use is directly linked to stylistic aspects arising from racial consciousness and identity. In this sense, it is assumed that linguistic marks of "pretuguês" (GONZALEZ, 1983), in hip hop, imply the existence of communities of this.

- KEYWORDS: Pretuguês; Nominal Agreement; Practice Comunnity; Racial identity.

\section{Introdução}

O presente trabalho visa apontar que a ausência de concordância nominal de número em sintagmas, como os mano, os cara e os homi, reflete aspectos estilísticos decorrentes de consciência racial e identitária, caso produzidos em contextos de

\footnotetext{
${ }^{1}$ Doutora em Língua e Cultura, pela UFBA. Professora Substituta de Linguística na Universidade Federal da Bahia. E-mail: f.cerqueira@ufba.br / f.cerqueira@hotmail.com.
} 
atividades e produtos do movimento cultural hip hop, bem como de suas comunidades de pertença, a qual trataremos aqui como dialeto hip hop. Deste modo,

[o] hip hop, para muito além da expressão inglesa que literalmente pode ser como hip - balançar e hop - quadril, tem sido compreendido como um movimento social juvenil urbano enraizado ao segmento populacional de baixo poder aquisitivo, a maioria negra e jovem, que historicamente ganha força nos Estados Unidos a partir do final dos anos de 1970 e posteriormente se espalha pelas grandes metrópoles do mundo (SOUZA, 2009, p. 21).

Outrossim, manifestações hip hop são marcadas por reflexão e por crítica a respeito da conjuntura de discriminação racial e socioeconômica, as quais jovens das periferias de grandes centros urbanos estão submetidos, por isso a expressividade de suas produções, dadas por meio de poesia, dança, música, escrita, imagem, linguagem e estética corporal, extrapola a esfera individual, manifestando-se a partir do agenciamento de quatro figuras, a saber, MC (Mestre Cerimônia), DJ (Disk Jockey), B-boy (dançarino) / B-girl (dançarina) e grafiteiro /grafiteira. Por sua vez, a filiação ideológica ao movimento hip hop, induz a esses sujeitos agenciamento com diversos signos constitutivos dessa filiação política e cultural, diretrizes de suas construções identitárias, tocando, não obstante, na produção linguística, como pode-se observar nos dados a seguir.

(1) Os mano lá na dois se ligaram na batida, mandaram acioná, mandaram um salve na rima.

(2) De esquina com os mano sempre em frente.

(3) RZO, os cara, rima rica, rima rara, os mano fica de cara e a batida que não para. Toda a família, a mesma família, os mano tudo da minha laia.

(4) Movimento rolando, os cara pixando.

(5) Sirele ligada os homi chegando, trick track, boom boom.

(6) Corre negada, os homi chegando.

(7) Que pros menor daqui eu sou espelho.

Os dados de (1) a (7), retirados de músicas das/das bandas/cantores Racionais MCs, RZO, Sabotage e Djonga ilustram uma modalidade linguística frequente nas periferias brasileiras, destacando-se, nesse caso, a variante de concordância zero para número em sintagmas nominais. Sabe-se que, em muitos casos, a uso dessa forma demonstra, conforme estudos sociolinguísticos tradicionais (SCHERRE; NARO, 1997; CALLOU, 1998; BAXTER; LOPES, 2009, entre outros), baixo acesso à norma considerada culta do português brasileiro (BAXTER, 2009; LOPES, 2015), evidenciando, nessa ótica, nuances do português popular brasileiro (MATTOS E SILVA, 2004; LUCCHESI, 2015), o qual apresenta forte aproximação com o português afrobrasileiro (LUCCHESI et al., 2009), ou, nos termos aqui propostos, pretuguês (GONZALEZ, 1983, 1988).

Entretanto, argumenta-se, no presente trabalho, que a ausência de concordância nominal de número, em contextos específicos, como em manifestações do movimento sociocultural hip-hop, remonta a questões de apropriação da variante em questão com fins de empoderamento ${ }^{2}$ racial por parte dos informantes, por conseguinte, configurando um grau de monitoramento orientado em função da concordância não marcada. Logo,

\footnotetext{
${ }^{2}$ Assumimos aqui que empoderamento seja um engajamento social que atua na emancipação em esfera individual, com vistas a resultar em emancipação em esfera coletiva, culminando, portanto, em um processo cíclico (BERTH, 2017).
} 
acredita-se que haja a escolha da variante zero e não que a ausência do uso canônico implique, exclusivamente, em baixo acesso à escolarização formal.

Para nortear a discussão supracitada acerca do fenômeno da concordância zero em sintagmas nominais, adotamos o método qualitativo de análise da terceira onda da sociolinguística (ECKERT, 2005, 2012) a fim de identificar, em dados extraídos de músicas, de cantores e bandas de $\mathrm{rap}^{3}$, que o uso de concordância de número não marcada nos sintagmas nominais supracitados está diretamente relacionado a aspectos estilísticos provenientes de consciência e identidade racial (ROTH-GORDON, 2007; CERQUEIRA, 2016) e empoderamento (HOOKS, 2008; SOUZA, 2011). Sendo assim, para discutir esse fenômeno linguístico, o trabalho divide-se em: 2. As três ondas da Sociolinguística; 3 . A emergência do pretuguês como língua de contato; 4. O pretuguês como comunidade de prática por meio do hip-hop; e 5. Conclusões.

\section{As três ondas da sociolinguística}

A Sociolinguística concebe a língua, como um sistema heterogêneo, passivo de variação e mudança, motivadas por fatores extralinguísticos, de ordem sociohistóricas, orientado, pelo menos em princípio, pela comunidade de fala. Consoante o pensamento de Labov (1972), é na comunidade de fala que a variação e a mudança ocorrem efetivamente, por isso

[...] uma comunidade de fala não pode ser concebida como um grupo de falantes que usam todos as mesmas formas, ela é mais bem definida como um grupo que compartilha as mesmas normas a respeito da língua [...] os membros de uma comunidade de fala compartilham um conjunto comum de padrões normativos, mesmo quando encontramos variação altamente estratificada na fala real (LABOV, 2002[1972], p. 188-189).

Observa-se, deste modo, que ao invés do uso linguístico compartilhado por falantes, as atitudes semelhantes diante de eventos linguísticos parece ser o critério adotado pelo autor para definir comunidade de fala. Considerando essa lacuna, Guy (2001) define comunidade de fala com base em três critérios: a. os traços linguísticos, compartilhados pelos falantes, devem diferenciá-los de outros grupos; b. entre os falantes do grupo, deve existir uma frequência alta de comunicação; e c. o grupo de falantes deve possuir as mesmas normas e as mesmas atitudes no que tange ao uso da língua.

Apesar de ampliar o conceito de comunidade de fala, o terceiro critério proposto por Guy (2001) se aproxima muito do conceito de comunidade de fala apresentado por Labov (1972). Todavia, o critério da frequência na comunicação abre precedente para outras possibilidades no campo teórico, como o conceito de redes sociais, proposto por Milroy (1980). Para a autora, as redes sociais são redes de relacionamentos desenvolvidas pelos informantes ao longo do cotidiano, estabelecidas em diferentes esferas, como família, grupo de amigos, campo profissional e tipos de lazer, por conseguinte, variam de falante para falante.

Uma grande contribuição de Guy (2001) à proposta de Milroy (2002) é de que a frequência comunicativa do falante é diretamente proporcional à densidade da rede na qual esse informante se insere, isto é, quanto maior o número de indivíduos atuantes em uma dada rede social, maior será a densidade dessa rede, por isso, quanto menor o número

\footnotetext{
${ }^{3}$ Rap é um gênero musical fortemente atrelado ao movimento hip hop, haja vista que é "[...] a poesia cantada que para existir precisa da junção de dois elementos: o DJ e o MC, [...] o poeta ou quem escreve e canta as letras de rap; já o DJ dá o tom ao discurso, que geralmente tematiza as desigualdades sociais, racismo, discriminações e violências de toda sorte" (SOUZA, 2009, p. 21).
} 
de indivíduos atuantes em uma determinada rede social, menor será a densidade dessa rede. Considerando que o conceito de rede foi originado na Antropologia, sua concepção está amplamente dependente de outras (macro)estruturas constitutivas da sociedade, tais como história, direito, economia, ideologia e política (CARNEIRO, 2005, ALMEIDA, 2018).

À vista disso, uma pesquisa sociolinguística, na qual se considere as redes sociais como ambiente comunicativo, visa capturar a dinâmica presente no comportamento interacional dos informantes. Assim, Coelho, Görski e Souza (2012) afirmam que tanto a pesquisa pautada no conceito de comunidade de fala, quanto a pesquisa desenvolvida, a partir da noção de rede social, apresentam alguns limites, pois no trabalho com comunidades de fala, prioriza-se o tipo social estratificado, e, no trabalho com redes sociais, há uma ampla dificuldade tanto com o levantamento, quanto com a sistematização dos grupos. Nessa ótica, a pesquisa com redes sociais, como proposta por Milroy (1980, 2002), tende a contemplar um número menor de informantes na constituição das amostras.

Atentando às questões supracitadas, Eckert (2000) propõe que os estudos em sociolinguística sejam constituídos a partir de comunidades de prática, espaços interacionais de construção de representações sociais nos quais a identidade, tanto do sujeito individualmente, quanto como membro de um dado grupo, encontra-se em processo dinâmico e constante de construção. Em sua proposta teórica, situada como prática social (LOPES, 2009), Eckert (2000, 2005, 2006) e Eckert e McConnell-Ginet (2010) consideram os informantes como sujeitos que, ao se inserirem em redes sociais, constituem categorias sociais e constroem constantemente o significado social da variação. Assim, as comunidades de prática consistem em "[...] um grupo de pessoas agregadas em função de um engajamento [social] mútuo e de um empreendimento comum [...]” (ECKERT, MCCONNELL-GINET, 2010, p. 102).

Em vista disso, a noção de sujeito proposta por Eckert (2000 e posteriores), segue a direção da concepção de sujeito pós-moderno, proposta por Hall (1992, p.12),

[...] o sujeito pós-moderno [é] conceptualizado como não tendo uma identidade fixa, essencial ou permanente. A identidade torna-se uma "celebração móvel": formada e transformada continuamente em relação às formas pelas quais somos representados ou interpelados nos sistemas culturais que nos rodeiam (HALL, 1987). É definida historicamente e, não biologicamente.

Sendo assim, o sujeito pós-moderno assume diferentes marcas identitárias, em diferentes circunstâncias, atravessadas por diferentes filiações ideológicas, de modo que as identidades não são "unificadas ao redor de um 'eu' coerente” (HALL, 1992, p. 13), mas em função dos perfis dos grupos com os quais dialoga. Nesse viés, para Eckert, os fenômenos da variação e da mudança linguística configuram-se como fruto de processos de constituição identitária dos falantes, haja vista que é nesse processo que as variáveis linguísticas assumem valor social. Diante disso, Eckert (2005) propõe que haja três ondas de estudos sociolinguísticos, as quais não se sucedem, nem se substituem, compartilham o mesmo objetivo geral de estudar a variação e a mudança em um sistema linguístico heterogêneo e plural, mas refletem um olhar mais particular de como estas abordagens lidam com a variação e com o informante, sob o prisma identitário.

A primeira onda está diretamente associada às produções labovianas. Os estudos dessa onda apresentam um vasto retrato das variáveis linguísticas usadas pela comunidade de fala, definida como entidade delimitada geograficamente nas quais "um grupo compartilha as mesmas normas a respeito da língua". Esse ainda é o modelo mais aderido pelos teóricos da sociolinguística, especialmente no Brasil, sendo, por sua vez, 
retratado como única vertente metodológica da teoria. Tal proposta iniciou-se com estudo de Labov (1966), acerca do inglês, em Nova York, trabalho em que a correlação do uso das variáveis linguísticas foi associada às categorias sociais primárias, a saber faixa etária, classe socioeconômica, gênero ${ }^{4}$ e etc, destacando o padrão regular da estratificação socioeconômica dessas variáveis, o que foi considerado como valor social da variação linguística. Tradicionalmente, estudos dialetológicos costumam recorrer aos aspectos metodológicos da primeira onda.

A segunda onda é fortemente marcada pelo caráter etnográfico cujas características possibilitam a percepção de um retrato local das variáveis linguísticas, pois, à medida que essas comunidades de fala estão situadas em comunidades menores, delimitadas mais antropologicamente, do que geoespacialmente, sua avaliação demanda a realização de um vasto mapeamento sociohistórico. Os trabalhos dessa onda, assumem, por sua vez, a definição de comunidade de fala proposta por Guy, na qual os traços linguísticos, compartilhados pelos falantes, deve diferenciá-los de outros grupos, entre os falantes do grupo, deve existir uma frequência alta de comunicação, e o grupo de falantes deve apresentar as mesmas normas e as mesmas atitudes no que concerne ao uso da língua.

Desta forma, os resultados das pesquisas em segunda onda representam um valor social relativo da variação de acordo com a dinâmica local. Por essa razão, Eckert (2005) e Freitag (2015) defendem que as produções em segunda onda promoveram uma visão mais precisa de como as variações diatópicas estão imbuídas de significado local, definido sociohistoricamente. Essa abordagem obteve muita adesão no âmbito da Crioulística, visto que a perspectiva etnográfica demanda uma coleta de dados realizada mediante maior envolvimento com a comunidade, assumindo, em função disso, elementos sociais e demográficos identificados com base em aspectos como saída da comunidade, julgamento de pertencimento e atitudes de modo geral. $\mathrm{O}$ trabalho mais citado como referência dessa perspectiva é o estudo de Labov (1966) sobre o black english, em Nova York, embora haja muitos outros.

A terceira onda visa estudar a variação linguística por meio das comunidades de prática as quais implicam na existência de uma identidade coletiva, decorrente de um grupo de pessoas agenciando um empreendimento comum a esse segmento social (ECKERT, MCCONNELL-GINET, 2010). Consequentemente, nessa abordagem, a variação é tratada como um fenômeno estilístico, proveniente de práticas linguísticas cotidianas, mutáveis em termos de significação e julgamento, mediante à filiação ideológica de quem as utiliza, em interação dinâmica, na condição de grupo. À vista disso,

\footnotetext{
[o]s estudos de $3^{\mathrm{a}}$ onda continuam quantitativos, valendo-se da experiência metodológica das ondas anteriores. A diferença está em intervir a ordem da pergunta: não mais buscar correlação entre o padrão linguístico e as categorias sociais, mas identificar as categorias sociais que atuam no padrão linguístico. É uma proposta de retomada do significado social da variação, mudando o foco da estrutura para a prática linguística (FREITAG, 2015, p.4).
}

\footnotetext{
${ }^{4}$ A variável gênero, tradicionalmente, é vista como o sexo biológico, desconsiderando a existência de sua construção social (DAVIS, 2016). Em vista disso, nos estudos em sociolinguística de primeira onda, a variável gênero é tratada como um indicador para mensurar, junto com a variável faixa etária, até que ponto uma variante é mais conservadora ou mais inovadora, pois acredita-se que "mulheres tendem a monitorar mais o seu comportamento linguístico do que os homens". Contudo, trabalhos como Chambers (1995), Eckert e McConnell-Ginet (2003), Carvalho (2014) e Carvalho e Brito (2020) problematizam e avançam sobre essa questão.
} 
As pesquisas dessa natureza consideram, como entidade linguística relevante para obtenção de amostras, as comunidades de práticas, grupo de sujeitos engajados em prol dos mesmos propósitos, pois compartilham as mesmas características, não só linguísticas, como e principalmente, ideológicas e identitárias, viabilizando, por conseguinte, a investigação do papel do sujeito em termos de "hierarquia, inovação e adesão" (COSERIU, 1979). Nessa ótica, a identidade demonstra o(s) papel(is) assumidos pelos sujeitos nos espaços em que atuam, ou seja, em suas comunidades de prática, "forjadas" partindo de suas redes sociais e, portanto, de suas relações de filiação.

\section{A emergência do pretuguês como língua de contato}

De acordo como Mufwene (2001, 2005, 2008), línguas humanas "nascem, crescem e morrem", na condição de espécies, tendo em vista que precisam estar "hospedadas" em seus falantes para garantia de sua vitalidade, ou seja, sua possibilidade de sobrevivência frente a condições de prestígio socioeconômico, a qual decorre da ecologia da língua/gem. Outrossim,

[...] nós podemos falar em nascimento, vitalidade e morte de línguas com propriedade apenas se as concebemos como espécies, mesmo que do tipo viral, cuja existência depende das práticas interacionais de seus falantes [...], que são seus criadores e seus hospedeiros. $\mathrm{O}$ foco na espécie em vez de nos organismos (tradicional desde o século XIX) é crucial porque mostra a importância da variação no interior de uma língua como uma extrapolação do que não passa de uma população de idioletos falados por indivíduos ao comunicarem uns com os outros. A vitalidade das línguas depende de quão regularmente as populações (que consistem de indivíduos), associadas a elas vêm a usá-las [...] (MUFWENE, 2016, p. 22).

Nessa perspectiva, a vitalidade, bem como a sobrevivência, de uma dada língua é fruto da ecologia dessa língua, isto é, a sociohistória das populações de falantes dessa língua e seu ambiente etnográficos induzem os falantes a optarem pelas línguas/modalidades linguísticas mais vantajosas em contextos específicos. Portanto, as estruturas sociais que atravessam dada comunidade linguística interferem na vitalidade e na sobrevivência das línguas ou modalidades linguísticas inseridas nesse cenário político cultural. Logo, "[t]oda mudança é motivada externamente. O que acontece internamente são rearranjos, pelo processo conhecido como regramaticalização" (MUFWENE, 2016, p.1), ou, nos termos de Aboh (2020), recombinação gramatical ${ }^{5}$.

Deste modo, para Mufwene (2016), a colonização europeia, iniciada, no século $\mathrm{XV}$, foi impulsionada por expansão econômica - ainda que sob a ótica de superexploração de terra e de corpos (MBEMBE, 2018) - proveniente de condições climáticas tropicais. Por conseguinte, a colonização teria atuado como fenômeno ecológico de modo a provocar morte de inúmeras línguas, ou linguicídio, nos termos de Rajagopalan (2010), haja vista que a dominação cultural, promovida pela escravização e pelo consequente genocídio de populações africanas e originais, impactou decisivamente na sobrevivência e na vitalidade das línguas hospedadas nos falantes destes povos.

À vista disso, a realidade sociolinguística brasileira, naturalmente, é notadamente marcada pelo contato multilíngue estabelecido, em situação de dominação, entre o

\footnotetext{
${ }^{5}$ Em linhas gerais, regramaticalização ou recombinação gramatical remontam à proposta do Bioprograma (BICKERTON, 1981, 1984), na qual a aquisição da modalidade linguística em curso - jargão, pidgin ou crioulo, já que não há consenso na literatura - como língua materna, no decorrer da colonização, resulta em uma nova língua, fruto de novas marcações paramétricas (ROBERTS, 1991; DEGRAFF, 1999; ABOH, 2015).
} 
Português Europeu (PE), como língua de superstrato, e as milhares de línguas indígenas e de línguas africanas. Assim,

[e]m seu passado de colônia agroexportadora, o Brasil guarda muitas
semelhanças sociohistóricas com outras regiões do continente americano,
como o Caribe e o Sul dos EUA, onde emergiram boa parte das línguas
crioula conhecidas atualmente no mundo. Essas línguas resultaram do contato
massivo, radical e abrupto desencadeado pelo sequestro e escravização de
cerca de dez milhões de africanos, trazidos para o continente americano pelos
colonizadores europeus, entre os séculos XVI e XIX (LUCCHESI, 2009, p.
28).

Todavia, na mesma direção que Mufwene (1996, 2002, 2016), Lucchesi (2009b) assume que o Português Brasileiro (PB) não seja uma língua crioula, pois, embora tenha ocorrido, no curso da colonização, contato linguístico massivo, abrupto e radical, teria havido, a partir de meados do século XIX, processo de recombinação gramatical, processo de ordem inata, caracterizado como gramática híbrida $(\mathrm{ABOH}, 2009,2015,2020)$, decorrente de inputs heterogêneos, situação recorrente em línguas emergidas em contexto de colonização.

Assim sendo, ainda que tenha ocorrido baixo acesso, das populações africanas e indígenas, à língua do colonizador - devido: a. ao número inexpressivo de população falante nativa de português, uma vez que apenas um terço da população brasileira era branca (NASCIMENTO, 1977, 1978); b. a maioria absoluta dos africanos escravizados era adulta (ALBUQUERQUE, 2004, 2009), decorrente de sistemas de plantations (KILOMBA, 2019), comprometendo em muitos aspectos o processo de aquisição; e c. ausência de ação normativizadora (LUCCHESI, 2009b) - também teria havido a reestruturação gramatical da modalidade "semi-crioula", resultado: a. da urbanização, promovendo fluxos migratórios; $b$. do surgimento da imprensa veiculando a norma de prestígio; e c. do incipiente acesso à escolarização básica em curso.

Em vista disso, fica claro que a formação do PB é fruto da ecolinguística imposta pelo sistema colonial, cuja base foi a escravização e, portanto, o racismo ${ }^{6}$,

[...] embora a segregação racial tenha sido implantada a fim de controlar efetivamente a população de escrav[izados] que, embora em larga medida transitória, sempre constituía a esmagadora maioria relativamente à população europeia” (MUFWENE, 2016, p. 27).

Consequentemente, ainda que em um modelo de sociedade essencialmente racista, as populações africanas e indígenas participaram ativamente da formação histórica e cultural do Brasil, o que, naturalmente, não escapa ao plano linguístico.

Sob essa ótica, com vistas a discutir a relevância de culturas africanas na composição etnográfica do Brasil, Gonzalez (1988) propõe a existência da categoria político-cultural de amefricanidade. Assim, a partir da discussão léxico-pragramática em torno do termo afroamericano, a autora toca em uma questão muito cara às teorias de formação do PB, a saber, a influência das línguas africanas em situação de contato linguístico, tanto durante, quanto após a escravização de populações negras. Deste modo,

\footnotetext{
${ }^{6}$ Processo discriminatório imposto à população negra, cujas características fenotípicas, atuam como herança de condições de subalternização, direta ou indireta, decorrentes do racismo estrutural, ou seja, a discriminação racial que extrapola a esfera do preconceito individual, marcando a coletividade por se caracterizar como pilar social, com base em ações nos campos da ideologia, da política, do direito e da economia (ALMEIDA, 2018).
} 
de acordo com Gonzalez (1988, p. 76), o item lexical afroamericano aponta para duas reflexões: "[...] a de que só existem negros nos Estados Unidos e não em todo o continente. E a outra, que aponta para a reprodução inconsciente da posição Imperialista dos Estados Unidos, que afirmam ser "A AMÉRICA".

Por esta razão, a autora propõe, como via de tensão para tal concepção de continente americano, a existência de uma "Améfrica" a qual existe "[...] enquanto sistema etnográfico de referência, [sendo] uma criação nossa e de nossos antepassados no continente em que vivemos, inspirados em modelos africanos" (GONZALEZ, 1988, p. 77). A derivação proposta por Gonzalez, como categoria política e cultural,

[...] incorpora todo um processo histórico de intensa dinâmica cultural (adaptação, resistência, reinterpretação e criação de novas formas), de maneira que suas referências estão em alguns modelos na América Latina, como é o caso do akan, na Jamaica, o yorubá, o banto e ewe-fon no Brasil (NASCIMENTO, 2019, p. 52).

Nessa ótica, um dos argumentos apresentadas por Gonzalez como evidência para o fenômeno da amefricanidade é a presença de marcas linguísticas de línguas africanas na "nova versão de língua alvo" adotada pelos povos colonizados da "Améfrica", como “ [o] caráter tonal e rítmico das línguas africanas trazidas para o Novo Mundo, além da ausência de certas consoantes (como o 1 ou o r, por exemplo) apontam para um aspecto pouco explorado da influência negra na formação histórico cultural do continente como um todo (e isto sem falar nos dialetos crioulos do Caribe) " (GONZALEZ, 1988, p. 70). No que tange, especificamente, ao $\mathrm{PB}$, a autora trata-o como pretuguês cuja razão incide na "[...] marca de africanização do português falado no Brasil" (GONZALEZ, 1988, p. $54)$.

É engraçado como eles gozam a gente quando a gente diz que é Framengo. Chamam a gente de ignorante dizendo que a gente fala errado. E de repente ignoram que a presença desse $r$ no lugar do $l$, nada mais é que a marca linguística de um idioma africano, no qual o $l$ inexiste. Afinal, quem é o ignorante? Ao mesmo tempo, acham o maior barato a fala dita brasileira, que corta os erres dos infinitivos verbais, que condensa você em cê, está em tá e por aí afora. Não sacam que tão falando pretuguês (GONZALEZ, 1983, p. 238).

Embora seu intuito não fosse refletir sobre fenômenos específicos da linguística, como rotacismo, reorganização do quadro pronominal do $\mathrm{PB}$, como a consequente redução do paradigma de concordância verbal, Gonzalez foi a primeira a fazer tal constatação no Brasil, sob a ótica do contato linguístico, considerando o segmento africano, ainda que sob o prisma etnográfico, uma vez que os debates que seguem, no campo da linguística, apontam ora para o preconceito linguístico (BAGNO, 1999), ora para a transmissão linguística irregular (LUCCHESI, 2003, 2011) e polarização sociolinguística (LUCCHESI et al, 2009). Isso posto, a partir de agora trataremos, tanto por filiação teórica, quanto política, as variantes linguísticas estigmatizantes de PB, decorrentes, conforme discutido, da influência de línguas africanas, como pretuguês, sobretudo, a concordância nominal não marcada, como apresentado nos dados (1-7).

\section{0 pretuguês como comunidade de prática por meio do hip hop}

Em estudo acerca do valor social de variantes estigmatizadas do inglês norteamericano, hooks (2008) discute a relação de língua e poder, especialmente, por meio de reflexões acerca do racismo, à medida em que identifica que as variantes estigmatizadas 
são aquelas produtivas entre a população negra, a qual, em virtude da escravização e, posterior, segregação legal, foi, historicamente, alijada, em sua maioria, de acessar a escolarização de qualidade.

Diante disso, hooks (2008) propõe a ressignificação destes usos linguísticos como emancipação do segmento social oprimido, isto é, aquela variante que, outrora era via de discriminação, passa a ser produzida com intuito de demarcar identidade, em função de uma prática de emancipação tanto individual, quanto coletiva, resultando em um processo de empoderamento.

Para tanto, a autora, incialmente, recusa a expressão "língua do opressor", com propósito de demarcar a função "desemponderadora" presente nesse campo discursivo, tendo em vista que é através da aquisição da língua de superstrato e de sua ressignificação, dada pelas variações, que o grupo dominado começa a reivindicar a língua como um elemento para sua constituição enquanto sujeito. Desta maneira,

[a]prender inglês, aprender a falar a língua estranha, era uma maneira de os escrav[izados] africanos começarem a recuperar seu poder pessoal dentro de um contexto de dominação. Possuindo a língua compartilhada, povos negros poderiam encontrar de novo uma maneira de fazer comunidades e um sentido para criar solidariedade política necessária para resistir [em situação de colonização] (HOOKS, 2008, p. 859).

O Estado estadunidense, no pós-abolição, implementou, no âmbito legislativo, o pacote de leis segregacionistas (DAVIS, 2016), pautado na leviana assertiva do "iguais mais diferentes", intitulado leis Jin Crown.

\begin{abstract}
As leis de Jim Crow foram leis estaduais promulgadas no sul do EUA, vigentes entre meados do século XIX e início do século XX, segundo as quais ambientes e repartições públicas disporiam de instalações separadas para brancos e negros, as quais foram de banheiros e bebedouros até intuições de ensino e ambientes de trabalho (CERQUEIRA, no prelo, p.7).
\end{abstract}

No Brasil, ainda que se argumente em função de uma democracia racial (FREYRE, 1933), no pós-abolição, sabe-se que, à proporção que a população negra recém "liberta" é impossibilitada de adquirir cidadania efetiva (NASCIMENTO, 1977), já que lhe foi negado direito à moradia, à educação, ao trabalho remunerado e regularizado e, portanto, ao capital, sua inserção à sociedade brasileira se dá através de sua marginalização (ALBUQUERQUER, 2004). Aliado a isso, a revisão do segundo código penal de 1980 prescreveu que

[...] "[e]xpressões culturais de negros", tais como capoeira, candomblé e funções monetárias desempenhadas por mulheres negras, como venda de quitutes, figuravam como crime de vadiagem (FLAUZINA, 2006; SAN'TANNA, 2006). Esta norma, atualmente compreendida como racismo institucional, comprometeu, das mais diversas formas, a população negra recém "liberta", vez que signos de negritude foram criminalizados, como vias alternativas de subsistência também o foram (CERQUEIRA, no prelo, p. 5).

Porquanto, observando, em linhas gerais, a institucionalização do racismo, como projeto nacional norte-americano e brasileiro, verifica-se diferentes perfis de hierarquia racial, atuando, principalmente, no plano da consciência desse fenômeno social (GONZALEZ, 1983). Não por acaso, o reconhecimento da população negra na formação do inglês norte-americano, black english (LABOV, 1972; SMITHERMAN, 1996), e do PB, pretuguês (GOZALEZ, 1983, 1988) ou português popular brasileiro (LUCCHESI, 
2015) também se dão de formas muito particulares. Esse evento, por sua vez, também afeta o curso da mobilização do uso de variantes linguísticas comumente estigmatizadas, por sua relação sociohistórica com línguas africanas, como instâncias de emancipação e empoderamento.

Tendo em vista que a colonização brasileira contou com mão de obra escravizada, composta por milhares de pessoas negras falantes de uma vasta gama de línguas africanas, segundo Lucchesi (2009b), esse cenário foi parcialmente favorável à presença de um crioulo. No entanto, a presença de ações normativas culminou em um processo de transmissão linguística irregular do qual resultou uma variedade de português e não uma língua crioula. Deste modo, as línguas faladas pelas comunidades quilombolas teriam sido crioulos de base lexical portuguesa, dissolvidos mediante aos efeitos das ações normativas, mas deixando fortes marcas nas normas populares, o elemento chave para o dialeto das periferias (LUCCHESI, 2015), uma vez que a formação das periferias, advinda da racialização do espaço urbano (SANTOS, 1987), deu-se pela presença da população negra recém-liberta e também desprovida de acesso massivo à escolarização. Nesse sentido,

[...] refletindo sobre as palavras de Adrienne Rich ["está é a língua do opressor, no entanto, eu preciso dela para falar com você’], eu sei que não é a língua inglesa que me fere, mas o que os opressores fazem com ela, como eles a moldam para se tornar um território que limita e define, como eles fazem dela uma arma que pode envergonhar, humilhar, colonizar (HOOKS, 2008, p. 857).

Entretanto, ainda que haja um processo de preconceito linguístico (BAGNO, 1999), tradicionalmente associado à variação diastrática, assumimos aqui que esse evento figura como racismo linguístico (NASCIMENTO, 2019), vez que é acarretado pelo uso de variantes mais produtivas entre falantes menos escolarizados e das menores camadas de estratificação socioeconômica, o quais, conforme sociohistória e ecolinguística apresentados, são maioria negra. Contudo,

[n]a cultura popular negra contemporânea, a música rap tem se tornado um dos espaços onde a fala vernácula negra é usada num estilo que convida a cultura padronizada dominante para escutar - ouvir - e, em algum grau, para ser transformada (HOOKS, 2008, p. 860).

À vista disso, assumimos que fenômenos da dita variação diastrática, quando produzidas intencionalmente, como marcas do pretuguês, na produção poética do rap brasileiro, como manifestações hip hop, em decorrência da sua marcante reflexão e crítica a respeito da discriminação racial e socioeconômica, refletem agenciamento desses sujeitos com diversos signos constitutivos dessa filiação política e cultural, diretrizes de suas construções identitárias, tocando, por sua vez, na produção linguística, possibilitando sua compreensão como comunidade de prática (ECKERT; MCCONNELL-GINET, 2010).

Considerando o hip hop como um movimento cultural da diáspora negra, Souza (2011) argumenta que não haja uma única perspectiva de surgimento do mesmo.

Ainda que não seja possível descrever precisamente o hip-hop por meio de uma única versão, uma das correntes mais expressivas afirma que o fenômeno consolida-se como cultura e obtém reconhecimento social e político a partir de seu surgimento nos bairros de Nova York nos anos, 1980, quando ganha contornos sociais e artísticos. Autores como Gilroy (2001), Hall (2003) e Cancline (2005) concordam com a ideia de que não existe apenas uma história 
do hip-hop. Como movimento cultural, ele se transforma nos vários contextos em que aporta, hibridiza-se e assume distintos formatos, ressignificando de maneiras diferentes os efeitos do fenômeno da diáspora negra pelo mundo, fazendo da musicalidade um dos elementos de sustentação de sua organização social, cultural e política (SOUZA, 2011, p. 60).

Por conseguinte, a emergência de valores referentes a esse movimento cultural, tais como discursos e atitudes, contribuem com o surgimento de códigos e orientações adotados por grupos à proporção que seus membros se juntam e ganham força "circunscritos a determinados bairros, originando crews, coletivos batizados com nomes que expressam novas identidades [coletivas] em construção" (SOUZA, 2011, p. 65), por isso o movimento hip hop é considerado híbrido e heterogêneo, uma vez que "se faz e refaz", principalmente, no cenário urbanos. No âmbito linguístico, segundo Cerqueira (2016), interpreta-se os mano como uma categoria, a classe de negros pobres, de maneira mais abrangente e em oposição aos playboy; enquanto os cara é um sintagma que atua, nesse dialeto, como um recorte da categoria "os mano" referente a indivíduos pertencentes ao mesmo grupo, porém, mais próximos, tais como "os broder", "os parceiro", "os parça"; e os homi, por sua vez, equivale refere-se tanto à categoria polícia, quanto a policiais em particular ${ }^{7}$.

Considerando comunidade de prática (ECKERT; MCCONNELL-GINET, 2010) como um grupo de falantes entre os quais é feito o mesmo engajamento cultural, oriundo de demandas sociais e políticas, em prol de relações de filiação, culminando, consequentemente, em comportamentos linguísticos e dada discussão sobre a natureza do movimento hip hop, bem como do rap, é legítimo considerá-lo como comunidade de prática. Portanto, fazer uso de variantes linguísticas, outrora estigmatizadas, revela, conforme aponta Cerqueira (2016), estilo, construção de uma persona social política, consciente das desigualdades raciais e econômicas brasileiras e, consequentemente, em apropriação do fenômeno de não marcação de concordância nominal de número, em determinados sintagmas, como elemento emancipatório (HOOK, 2008), produzindo, em seu uso, novos sentidos oportunos para condições de empoderamento.

\section{Conclusão}

No presente trabalho, assumimos que marcas linguísticas do pretuguês (GONZALEZ, 1983, 1988), presentes no rap, como manifestação poética do movimento político cultural hip hop, implicam na existência de comunidades de prática (ECKERT; MCCONNELL-GINET, 2010). Nessa ótica, compreendemos que o fenômeno da ausência de concordância de número em sintagmas nominais, como os mano, os cara, os menor e os homi, reflete aspectos estilísticos decorrentes de identidade racial, quando produzidos no dialeto hip hop (SOUZA, 2009, CERQUEIRA, 2016). Para isso, foi adotado o método qualitativo de análise, da terceira onda da sociolinguística (ECKERT, 2005, 2012), o qual possibilitou a identificação de que o uso de concordância de número não marcada em sintagmas nominais está amplamente relacionado à performance estilística de língua(gem), oriundas de consciência e identidade racial. Logo, a variação, aqui, é concebida como prática estilística, decorrentes das práticas linguísticas cotidianas, passivas de mudança, quanto à significação e ao julgamento, haja vista que, nessa ceara, a variante estigmatizada é ressignificada como emancipatória (HOOKS, 2008).

\footnotetext{
${ }^{7}$ É importante destacar que o significado social do sintagma nominal com concordância zero, os homi, representa uma variante circunscrita em um projeto de sociedade genocida, orientado pelo controle de corpos subalternizados, por meio Estado e seus agentes (MBEMBE, 2018), em que se naturaliza que a cada vinte e três minutos um jovem negro seja assassinado (CARNEIRO, 2019; RIBEIRO, 2018).
} 


\section{REFERÊNCIAS}

ABOH, E. O. Competition and selection: That's all. In: ABOH, E. O.; SMITH, N. (Eds.). Complex Processes in New Languages. Amsterdam: Benjamins, 2009, p. 317-344. The Emergence of Hybrid grammar: Language Contact, Change and Creation. Cambridge: Cambridge University Press, 2015.

Lessons From Neuro-(a)-Typical Brains: Universal Multilingualism, CodeMixing, Recombination, and Executive Functions. Front. Psychol,, v. 11, 488, 2020. ALBUQUERQUE, W. A exaltação das diferenças: racialização, cultura e cidadania brasileira (Bahia, 1880 - 1900). Tese (Doutorado em História) - Instituto de Filosofia e Ciências Humanas, Universidade do Estado de Campinas, Campinas, 2004.

O jogo da dissimulação: Abolição e cidadania negra no Brasil. São Paulo: Companhia das Letras, 2009, p. 247-283.

ALMEIDA, S. O que é racismo estrutural? Coleção Feminismos Plurais. Belo Horizonte: Editora Letramento, 2018.

BAXTER, A. A concordância de número. In: LUCCHESI, D; BAXTER, A.; RIBEIRO, I. O português afro-brasileiro. Salvador: EDUFBA, 2009, p. 41-74.

BAGNO, M. Preconceito Linguístico: o que é? como se faz? São Paulo: Loyola, 1999. BAXTER, A: LOPES, N. O desenvolvimento de regras de concordância variável em variedades de Português a partir de modelos-estímulos (inputs) diferentes. In: LOBO, T; CARNEIRO, Z.; SOLEDADE, J.; ALMEIDA, A.; RIBEIRO, S. (Orgs.). ROSAE: Linguística histórica, história das línguas e outras histórias, 2009, p.221-238.

BICKERTON, D. Roots of language. Ann Arbor: Karoma, 1981.

. The Language Bioprogram Hypothesis. Behavioural and Brain Sciences, Cambridge, n.7, 1984, p. 173-203.

CERQUEIRA, F. O. Os Mano, Os Cara, Os Homi: Concordância, Identidade e Consciência Racial. In: LOPES, N. S.; PARCERO, L. M. J.; CARVALHO, C. S. Anais do VI Encontro de Sociolinguística: Estudos sobre a relação entre língua e sociedade. Salvador: PPGEL, 2016, p. 82-93.

Cotas raciais: entre o racismo e o colorismo. No prelo.

CALLOU, D. M. I. Um estudo em tempo real em dialeto rural brasileiro: questões morfossintáticas. In: GROBE, S.; ZIMMERMANN, K. (Eds.). "Substandard" e mudança no português do Brasil. Frankfurt am Main: TFM, 1998, p. 255-272.

CARNEIRO, A. S. A construção do outro como não-ser como fundamento do ser. Tese (Doutorado em Educação) - Faculdade de Educação, Universidade de São Paulo, São Paulo, 2005.

. Escritos de uma vida. São Paulo: Pólen Livros, 2019.

CARVALHO, D. S. A língua na diversidade: um estudo sociolinguístico de gays soteropolitanos. Projeto de Pesquisa, Salvador: DFEL - UFBA, 2014.

CARVALHO, D.; BRITO, D. (Eds.). Gênero e Língua(gem): formas e usos. Salvador: Edufba, 2020.

COSERIU, E. Sincronia, diacronia e história: o problema da mudança linguística. Rio de Janeiro: Presença, 1979.

CHAMBERS, J. K. Sociolinguistic Theory. Blackwell: Oxford, 1995.

DAVIS, Ângela. Mulheres, Raça e Classe. Tradução de Heci Regina Candiani. São Paulo: Boitempo, 2016.

DEGRAFF, M. Creolization, language change, and language acquisition: an epilogue. In: DEGRAFF, M. (Ed.). Language creation and language change: creolization, diachrony, and development. Cambridge: The MIT Press, 1999. p. 473-544.

ECKERT, P. Linguistic Variation as social practice. Oxford: Blackwell, 2000. 
Style and social meaning. In: ECKERT, P.; RICKFORD, J. Style and sociolinguistic variation. Cambridge: Cambridge University Press, 2001, p. 119-126. Variation, convention and social meaning, Paper Presented at the Annual Meeting of the Linguistic Society of America. Oakland CA, Jan. 2005.

Communities of Practice, In: BROWN, K.; ANDERSON, A. H. (Eds.). Encyclopedia of Language and Linguistics, Elsevier: Oxford, 2006, v. 2, p. 683-685. Three waves of variation study: the emergence of meaning in the study of sociolinguistics variation. Annual review of Anthropology, 2012, n. 41, p. 87-100.

ECKERT, P.; McCONNELL-GINET, S. Language and Gender. Cambridge: Cambridge University Press, 2003.

Variation, convention and social meaning, Paper Presented at the Annual Meeting of the Linguistic Society of America. Oakland CA, Jan. 7. __ 2006. Communities of Practice, In: BROWN, K. ; ANDERSON, A. H. (Eds.). Encyclopedia of Language and Linguistics. Oxford: Elsevier, 2005, v. 2, p. 683-685.

. Comunidades de práticas: lugar onde co-habitam linguagem, gênero e poder, In: OSTERMANN, A. C.; FONTANA, B. Linguagem, gênero e sexualidade: clássicos traduzidos, São Paulo: Parábola, 2010, p. 93-107.

FREITAG, R. M. K. Prefácio: Atitudes e Identidade Linguística: muito chão pela frente. In: Atitudes Linguísticas e Avaliações Subjetivas de Alguns Dialetos Brasileiros. São Paulo: Blucher, 2015, p. 3-8.

FREYRE, G. Casa-grande \& senzala. 42. ed. Rio de Janeiro: Record, 2001 [1933].

GONZALEZ, L. Racismo e sexismo na cultura brasileira. Revista Ciências Sociais Hoje, ANPOCS, 1983, p. 223-244.

A categoria político-cultural de amefricanidade. Tempo Brasileiro, Rio de Janeiro, n. 92-93, 1988, p. 69-82.

GUY, G. As comunidades de fala: fronteiras internas e externas. In: II Congresso Internacional da ABRALIN, Fortaleza. Anais, 2001.

HALL, S. A identidade em questão. In: HALL, S. A identidade cultural na pós modernidade. Rio de Janeiro: DP\&A editora, 1992, p.7-13.

HOOKS, B. Linguagem: ensinar novas paisagens/novas linguagens. In: Estudos Feministas, v.16(3), 2008.

KILOMBA, G. Memórias da Plantação: episódios de racismo cotidiano. Trad. Jess Oliveira. Rio de Janeiro: Editora Cobogó, 2019.

LABOV, W. The social stratification of English in New York City. New York: Cambridge University Press, 1966.

1972.

Sociolinguistic Patterns. Philadelphia: University of Pennsylvania Press,

LOPES, M. Da aplicação da Linguística à Linguística Aplicada. In: PEREIRA, R. C. Linguística Aplicada: um caminho com diferentes acessos. São Paulo: Contextos, 2009. LOPES, N. O mecanismo da variação da concordância no Português: observações quanto a marcas nos verbos e nos nomes. Estudos da Língua(gem). Vitória da Conquista, v. 13, n. 2, 2015, p. 59-72.

LUCCHESI, D.; BAXTER, A.; RIBEIRO, I. O português afro-brasileiro. Salvador: EDUFBA, 2009.

A transmissão linguística irregular. In: LUCCHESI, D; BAXTER, A.;

RIBEIRO, I. O português afro-brasileiro. Salvador: EDUFBA, 2009b, p. 41-74.

Língua e sociedades partidas: a polarização sociolinguística do Brasil. São

Paulo: Contexto, 2015.

SILVA, R. V. M. Ensaios para uma sócio-história do português brasileiro. São Paulo: Parábola Editorial, 2004. 
MATTOS E SILVA, Rosa Virgínia. O português no Brasil: sua formação na complexidade multilinguística do Brasil colonial e pós-colonial. Leituras Contemporâneas, Salvador, v. 1, n. 1, p. 95-105, 2004.

MBEMBE, A. Necropolítica. São Paulo: N-1 edições, 2018.

MILROY, L. Language and Social Networks. Oxford: Blackwell, 1980.

Social Network. In: CHAMBERS, J.K; TRUGDILL, P.; SCHILLINGESTES, N. (Eds.). The handbook of language variation and change. Oxford: Blackwell, 2002, p. 549-571.

MUFWENE, S. S. The founder principle in creole genesis. Diachronica, 13:1, 1996, p. 83-134.

. Language birth and death. Annual Review of Anthropology, 33, 2004, p. 201222.

Press, 2008.

Language evolution: Contact, competition and change. London: Continuum

Ecologia da língua: algumas perspectivas evolutivas. Ecolinguística: Revista

Brasileira de Ecologia e Linguagem, v. 02, n. 01, 2016, p. 21-38.

NASCIMENTO, A. Democracia racial: mito ou realidade? 1977.

O genocídio do negro brasileiro. Rio de Janeiro: Paz e Terra, 1978.

NASCIMENTO, G. Racismo Linguístico: os subterrâneos da linguagem e do racismo. Belo Horizonte: Letramento, 2019.

RAJAGOPALAN, K. The English Language, Globalization and Latin America: possible lessons from the "uter Circle. In: OMINYI, T.; SAXENA, M. (Eds.). Forthcoming: World Englishes and Globalization, 2010.

RIBEIRO, D. Quem tem medo do feminismo negro? São Paulo: Companhia das Letras, 2018.

ROBERTS, I. Creoles, markedness and the Language Bioprogram Hypothesis. Estudos Linguísticos e Literários, Salvador, n.19, p.11-24, 1997

ROTH-GORDON, J. Racing and erasing the playboy: slang, transnacional, youth subculture and racial discourse in Brazil. Jornou of Linguistic Anthropology, v. 17, 2007. SCHERRE, M; NARO, A. A concordância de número no português do Brasil: um caso típico de variação inerente. In: HORA, D. (Org.). Diversidade lingüística do Brasil. João Pessoa: Idéia, 1997, p. 93-114.

SOUZA, A. L. S. Letramentos reexistência: culturas e identidades no movimento hip hop. Tese (Doutorado em Linguística Aplicada) - Instituto de Estudos da Linguagem, Universidade do Estado de Campinas, Campinas, 2009.

Parábola, 2011

- Letramentos de resistência: poesia, grafite, música, dança. São Paulo:

SANTOS, M. Espaço do Cidadão. São Paulo: Nobel, 1987.

SMITHERMAN, G. African-American English: From The Hood to the Amen Corner, Speaker Series, n 5, 1996.

Recebido em: junho de 2020. Aprovado em: agosto de 2020.

Como citar este trabalho:

CERQUEIRA. F. de O. O pretuguês como comunidade de prática: concordância nominal e identidade racial. Traços de Linguagem, v. 4, n. 1, p. 75-88, 2020. 